This PDF is a selection from an out-of-print volume from the National Bureau of Economic Research

Volume Title: Money in Historical Perspective

Volume Author/Editor: Anna J. Schwartz

Volume Publisher: University of Chicago Press

Volume ISBN: 0-226-74228-8

Volume URL: http://www.nber.org/books/schw87-1

Publication Date: 1987

Chapter Title: Has Government Any Role in Money?

Chapter Author: Milton Friedman, Anna J. Schwartz

Chapter URL: http://www.nber.org/chapters/c7507

Chapter pages in book: (p. $289-314)$ 


\title{
12 Has Government Any Role in Money?
}

\author{
Milton Friedman and Anna J. Schwartz
}

\subsection{Introduction}

In recent years there has been a burst of scholarly interest in various aspects of monetary reform-not the conduct of current monetary policy, which has for decades been the object of active scholarly work, but the institutional structure of the monetary system. This interest has centered on three separate but related topics: (1) competition versus government monopoly in the creation of or control over outside or high-powered money, (2) so-called free banking, and (3) the determination of the unit of account and its relation to media of exchange. The topics are related because they all deal with what role, if any, government has in the monetary system.

This burst of interest has been a response to mutually reinforcing developments, some internal to the discipline of economics; others, external.

The internal developments were threefold. One is the emergence of the theory of public choice, which has produced a large-scale shift from a public-interest to a private-interest interpretation of government activity. Instead of regarding civil servants and legislators as disinterestedly pursuing the public interest, as they judged it-in sharp contrast to the behavior we have attributed to participants in business enterprises-economists have increasingly come to regard civil servants and legislators as pursuing their private interests, treated not as narrowly pecuniary or selfish but as encompassing whatever ends enter into their utility functions, not excluding concern for the public interest. This public choice perspective is extremely attractive intellectually because it aligns our interpretations of government and private activity. It has inevitably led to extensive research on the determinants of govern- 
mental behavior as well as to renewed attention to the kinds of institutions and policies, if any, that can make each participant in government as in a free market operate as if, in Adam Smith's famous phrase, he were "led by an invisible hand to promote an end that was no part of his intention," namely, the interest of the public. Monetary policy and the monetary authorities have been obvious candidates for attention. ${ }^{1}$

A second internal development is the rational expectations approach, particularly its stress on the effect of the institutional structure and changes in the institutional structure on the expectations of the public. In one sense, this approach is not new. For example, the effect of the existence of central banks on the behavior of commercial banks and the public had long been explicitly recognized in the monetary literature. Yet, the coining of a new name, the application of the idea by Lucas to the validity of econometric forecasts, and the explicit modelling of the role of expectations have all had a major impact on the profession's thinking and, incidentally, have promoted greater attention to institutional structures as compared with current policy formation.

A third internal development is the renewed interest in so-called Austrian Economics, with its emphasis on invisible-hand interpretations of the origin and development of economic institutions, and its interpretation of the business cycle as largely reflecting the effect of non-neutral money. The latter in turn produced a long "Austrian" tradition of support for "hard" money and opposition to discretionary money management. Hayek's proposal $(1976,1978)$ for denationalizing money was especially influential in reviving this tradition.

The key external development- the ultimate consequences of which are shrouded in uncertainty-was the emergence of a world monetary system that, we believe, is unprecedented: a system in which essentially every currency in the world is, directly or indirectly, on a pure fiat standard-directly, if the exchange rate of the currency is flexible though possibly manipulated; indirectly, if the exchange rate is effectively fixed in terms of another fiat-based currency (e.g., since 1983, the Hong Kong dollar). This system emerged gradually after World War I. From then to 1971, much of the world was effectively on a dollar standard, while the U.S., though ostensibly on a gold standard (except for a brief interval in 1933-34), was actually on a fiat standard combined with a government program for pegging the price of gold. The Bretton Woods agreement in the main simply ratified that situation, despite the lip service paid to the role of gold, and the provisions for changes in exchange rates. The end of Bretton Woods in 1971 removed both the formal links to the dollar and the pretense that the U.S. was on a gold standard. The stocks of gold listed on the books of the central books of the world are a relic of a bygone era, though a slim possibility remains that they will again become more than that at some future date. 
The formal ending of Bretton Woods was precipitated by an inflationary surge in the U.S. in the 1960s and in turn helped to produce a continuation and acceleration of that surge in the 1970s. The inflation and the subsequent economic instability were more directly responsible for the burst of interest in monetary reform than the momentous change in the world's monetary system of which the inflation was both a cause and a manifestation. It did so in several ways. In the first place, it brought into sharp focus the poor performance of the monetary authorities-reinforcing the conclusions about prior policy that various scholars had reached, including ourselves in our Monetary History. Even granted the market failures that we and many other economists had attributed to a strictly laissez-faire policy in money and banking, the course of events encouraged the view that turning to government as an alternative was a cure that was worse than the disease, at least with existing government policies and institutions. Government failure might be worse than market failure.

In the second place, the rise in nominal interest rates produced by the rise in inflation converted government control of interest rates in the U.S. via Regulation $Q$ from a minor to a serious impediment to the effective clearing of credit markets. One response was the invention of money market mutual funds as a way to avoid Regulation $Q$. The money market funds performed a valuable social function. Yet, from a broader perspective, their invention constituted social waste. If either the inflation had not occurred or banks had been free to respond to market forces, there would have been no demand for the services of money market funds, and the entrepreneurial talent and other resources absorbed by the money market mutuals could have been employed in socially more productive activities. The money market funds proved an entering wedge to financial innovations that forced a relaxation and near-abandonment of control over the interest rates that banks could pay, as well as over other regulations that restricted their activities. The deregulation of banking that has occurred came too late and has been too incomplete to prevent a sharp reduction in the role of banks, as traditionally defined, in the financial system as a whole.

In Friedman's Program for Monetary Stability, published a quarter of a century ago, he asked the question "whether monetary and banking arrangements could be left to the market, subject only to the general rules applying to all other economic activity."

"I am by no means certain," he wrote, "that the answer is indubitably in the negative. What is clear is that monetary arrangements have seldom been left entirely to the market, even in societies following a thoroughly liberal policy in other respects, and that there are good reasons why this should have been the case" [Friedman (1959, p. 4)]. Those "good reasons" were: "[1] the resource cost of a pure com- 
modity currency and hence its tendency to become partly fiduciary; [2] the peculiar difficulty of enforcing contracts involving promises to pay that serve as a medium of exchange and of preventing fraud in respect to them; [3] the technical monopoly character of a pure fiduciary currency which makes essential the setting of some external limit on its amount; and finally, [4] the pervasive character of money which means that the issuance of money has important effects of parties other than those directly involved and gives special importance to the preceding features. Something like a moderately stable monetary framework seems an essential prerequisite for the effective operation of a private market economy. It is dubious that the market can by itself provide such a framework. Hence, the function of providing one is an essential governmental function on a par with the provision of a stable legal framework" [Friedman $(1959$, p. 8), numbers added].

Of course, recognition that there are "good reasons" for government to intervene and that, as a matter of historical fact, governments, and especially modern governments, almost invariably have done so, does not mean that the actual interventions have promoted the public welfare, or that the modes of intervention have been wisely chosen. A major aim of our Monetary History was precisely to investigate this question for the U.S. for the period after the Civil War.

The evidence we assembled strongly suggests, indeed we believe demonstrates, that government intervention was at least as often a source of instability and inefficiency as the reverse, and that the major "reform" during the period, the establishment of the Federal Reserve System, in practice did more harm than good. Our personal conclusion, reinforced by the evidence in that work though not stated therein, is that a rigid monetary rule is preferable to discretionary monetary management by the Federal Reserve.

The aim of this paper is to consider whether the new evidence and new arguments that have emerged in recent years justify a revision of the earlier summary of "good reasons" why government has intervened, in particular of the conclusion that "the market itself cannot provide" a "stable monetary framework." In the most extreme form, does the evidence justify an unqualified affirmative rather than negative answer to the question "whether monetary and banking arrangements cannot [i.e., should not] be left to the market"?

This question in turn breaks down into three separate questions, the clear differentiation of which is one of the valuable contributions of recent writings:

(1) Can and should the determination of a unit of account linked with a medium of exchange and the provision of outside money itself be left to the market or do items [1], [3], and [4] of Friedman's 
good reasons justify a government role in defining the unit of account and providing an outside money?

(2) Given a well-defined outside money involving a unit of account and a medium of exchange, can and should strict laissez-faire be the rule for banking - broadly defined to include the issuance of inside money in the form of currency as well as deposits-except only for the general rules applied to all other economic activity? This is the so-called free-banking question, which bears particularly on items [2] and [4] of Friedman's "good reasons."

In terms of institutional and legal arrangements, the major subissues are:

(1) Should financial intermediaries be prohibited from issuing inside money in the form of hand-to-hand currency, i.e., should hand-to-hand currency be a government monopoly?

(b) Are governmental limitations on lending and investing by financial intermediaries necessary or desirable?

(c) Is a government "lender of last resort"-a central banknecessary or desirable?

(3) In the absence of legal obstacles, can, should, and would the unit of account be separated in practice from the medium of exchange function in the belief that financial innovation will render outside money unnecessary and obsolete? I.e., do financial innovations promise to make a 100 percent inside money the most efficient means of engaging in transactions?

It may be worth noting explicitly that the word "can" as used in these questions admits of two very different interpretations. One is narrowly economic: is a given set of arrangements internally consistent so far as narrowly economic conditions are concerned; that is, would it generate a stable equilibrium, both static and dynamic? The other is broader. Would the set of arrangements generate a stable political as well as economic equilibrium; that is, is its existence consistent with the political constitution, or would it generate political forces leading to major changes in the arrangements?

We believe that failure to distinguish between these interpretations is responsible for much of the appearance of disagreement in the discussions of monetary reform.

Of the three questions posed, we propose to discuss the first two, since the third is much less related to our earlier work, and besides, has been dealt with recently, and in our opinion correctly, by others [McCallum (1985) and White (1984b)].

The first and third questions are new in a sense in which the second is not. Essentially all participants in the nineteenth- and early twentiethcentury controversies about monetary and banking matters took for granted a specie standard, in which government's role was restricted to coinage or its equivalent (i.e., provision of warehouse receipts for 
specie); hence they never had occasion to consider the first and third questions. Suspension of specie payments was regarded as, and in fact generally was, a temporary expedient to meet a temporary difficulty. Any government-issued money (whether notes or deposits) in excess of specie reserves was, in modern terminology, regarded as inside money, not outside money, though it clearly became the latter during periods of suspension of specie payments. This common view no doubt reflected widespread agreement that historical experience showed, as Irving Fisher put it in 1911, that "Irredeemable paper money has almost invariably proved a curse to the country employing it" [see Fisher $(1929$, p. 131)].

The disappearance of specie standards and the emergence of a world monetary system in which, for the first time, every country is, in Fisher's terms, on an "irredeemable paper standard" has produced two very different streams of literature: one, scientific; the other, popular. The scientific literature is that already referred to, dealing with monetary reform and the government's role in providing outside money (section 12.2 below). The popular literature is alarmist and "hard money," essentially all of it based on the proposition that Fisher's generalization will continue to hold and that the world is inevitably condemned to runaway inflation unless and until the leading nations adopt commodity standards.

There has been some, but limited, intersection between these two streams. The scientific literature has occasionally dealt with but mostly ignored the question raised by the popular literature. Have the conditions that have produced the current unprecedented monetary system also altered the likelihood that it will go the way of earlier paper standards? We consider that question in a tentative way in section 12.4 below.

By contrast with outside money, free banking was fully and exhaustively discussed in the nineteenth and early twentieth century. Recent literature has added much historical detail, discussed the arguments in terms of current monetary arrangements, and expressed old arguments in more formal and abstract terms. And we now have a much wider span of historical experience on which to base a judgment. Nonetheless, Vera Smith's 1936 Rationale of Central Banking provides, we believe, as accurate and complete a summary of recent theoretical arguments for and against "free banking" as it does of the earlier arguments (section 12.3).

\subsection{Outside Money}

Whether the government has a role in providing outside money, and what that role should be, is more basic than whether government should 
intervene in the provision of inside money by non-government banking institutions. Existing banking systems rest on the foundation of an outside money, and so did those "free banking" systems, such as the Scottish, Canadian and early U.S., that have recently been subjected to reexamination and offered as object lessons. Historically, a single unit of account linked to a single dominant outside money has tended to emerge, initially via a market process of transactors settling on a particular commodity, followed almost invariably by government's exercising control over one or more aspects of the issuance of outside money-typically with the ostensible purpose of standardizing the coinage and certifying its quality (purity, fineness, etc.). Occasionally, two commodities, with a flexible rate of exchange between them, have simultaneously been outside moneys, one for small transactions, the other for large, as with silver and gold in the Middle Ages, or copper and silver in China.

Insofar as governments confined themselves to producing standardized coinage, the activity was a source of revenue because of the convenience to the public of using for transaction purposes coins with a stated face value rather than bullion. The mint could make a "seignorage" charge for providing this service, and the government's visibility and authority gave it an advantage over private mints even when it did not prohibit them. However, governments have repeatedly gone farther and have used (or abused) their control over outside money to raise revenue by introducing fiat elements. Initially, this took the form of the debasement of the metallic coinage issued by the sovereign - that is, increasing the proportion of base metal in silver and gold coins, so that the stated face value of the coins exceeded the market value of the precious metal they contained. Such debasement was a source of revenue because of the lag in the adjustment of nominal prices to the lowered precious metal content of the coins. During this period, the base metal served, as it were, as inside money.

The introduction and subsequent widespread use of paper money and deposits, initially as warehouse receipts for specie, opened a broader range of possibilities, exploited both by private individuals or bankers who issued notes and deposits promising to pay specie on demand in excess of the amount of specie they held (private inside money, so long as the issuers honored the promise), and by governments that did the same (government inside money, subject to the same proviso).

As banking developed, commercial banks came to regard all noninterest bearing government issues-in the U.K., notes and deposits at the Bank of England; in the U.S., United States notes (greenbacks), national bank notes, silver certificates, Federal Reserve notes and deposits-as outside money. However, for the system as a whole, so long as convertibility into specie was maintained, only specie was in fact 
outside money; the excess of government issues over the government's specie holdings was government-created inside money. All such issues, however, became true outside money-pure fiat money-when convertibility was suspended, as it now has been throughout the world.

We still refer to government-issued non-interest bearing notes and deposits as government "liabilities" or "obligations," although that is not what they are, as is eminently clear in other contexts. We now take a pure fiat standard so much for granted that we no longer find any need to distinguish between the concepts of outside money relevant for the commercial banks and for the system as a whole. But that distinction remains important in judging proposals for monetary reform, and in interpreting historical experience.

That experience provides striking evidence of the value that communities attach to having a single unit of account and medium of exchange. The large revenue that governments have been able to extract by introducing fiat elements into outside money is one measure of the price that economic agents are willing to pay to preserve the unit of account and the medium of exchange to which they have become habituated. It takes truly major depreciation in the purchasing power of the dominant money before any substantial fraction of the community adopts alternatives, either with respect to the unit of account or the medium of exchange. Yet such alternatives have generally been available.

For example, students of money have repeatedly recommended what Alfred Marshall called a tabular standard, namely, the indexation of long-term contracts, so that for such contracts the unit of account becomes, to use one currency as an example, not the nominal dollar, but the real dollar, although the medium of exchange may remain the nominal dollar. ${ }^{2}$ In most Western countries, nothing has prevented the private emergence of a tabular standard. Yet, a tabular standard has emerged on any widespread scale only in countries that have been subject to extreme movements in the price level, like some Latin American countries, Israel, etc. Indexation has been privately introduced on any substantial scale in the U.S. only with respect to labor contracts, and even there only occasionally and with respect to a minority of contracts.

Another alternative has been foreign currency, which has occasionally been resorted to both as unit of account and medium of circulation, but again only under extreme provocation.

The apparently great value to the economy of having a single unit of account linked with an (ultimate) medium of exchange does not mean that government must play any role, or that there need be a single producer of the medium of exchange. And indeed, historically, governments have entered the picture after the event, after the community had settled on a unit of account and private producers had produced media of exchange. 
Two features of this history are striking. The first is that the unit of account has, invariably or nearly so, been linked to a commodity. We know of no example of an abstract unit of account-a fiduciary or fiat unit such as now prevails everywhere, having emerged spontaneously through its acceptance in private transactions. The second is how universally government has taken over, and how often it has established a monopoly in the certification or production of the outside money. In his explanation of this phenomenon, Friedman stressed considerations of economic efficiency-"can" in the narrower economic sense. But this is clearly inadequate. The theory of public choice requires attention to the political forces that have produced this result and the kind of monetary constitution, if any, that can avoid it. ${ }^{3}$ It is not enough to document the abuses that have arisen from government control of outside money, or to demonstrate the existence of alternative arrangements that are economically more satisfactory. We shall be evading our task of explanation unless we examine the political forces that established government control under a wide range of political and economic circumstances, superseding private certification and production of outside money. And, so far as reform is concerned, we shall simply be spitting in the wind, as economists have done for 200 years with respect to tariffs, unless we explore how effective political support can be mobilized for one or another solution. We hasten to add that the latter is not the task of this paper. ${ }^{4}$

Item [3] of Friedman's list of "'good reasons," the technical monopoly character of a pure fiduciary currency (italics added) has been questioned, particularly by Benjamin Klein (1974). Klein's theoretical case, resting on the necessity for a producer of money to establish confidence in his money, and the increasing capital cost of creating such confidence, is impeccable, and has received wide acceptance. Yet it is not clear that his argument can be carried over to a "pure fiduciary" currency. ${ }^{5}$ Historically, producers of money have established confidence by promising convertibility into some dominant money, generally, specie. Many examples can be cited of fairly long-continued and successful producers of private moneys convertible into specie. ${ }^{6}$ We do not know, however, of any example of the private production of purely inconvertible fiduciary moneys (except as temporary expedients, e.g., wooden nickels, clearing house certificates), or of the simultaneous existence in the same community of private producers of moneys convertible into different ultimate media, except for the previously mentioned case when two metals circulated simultaneously at a flexible rate of exchange, and the somewhat similar case of the greenback period (18621878 ) in the U.S. when banks had both greenback and gold deposit liabilities. Yet Klein's argument would not seem to preclude the simultaneous existence in the same community of several dominant moneys produced by different private issuers. 
Hayek, in his argument for the denationalization of money, believes that such an outcome is a real possibility, if the current legal obstacles to the production of competitive moneys were removed. In particular, he believes that private issuers who produced a medium of exchange with constant purchasing power (a "real dollar") would become dominant. He recognizes that a single dominant money might tend to develop over large areas, but anticipates that different definitions of constant purchasing power would be appropriate for different areas or groups and hence that a "number of different competitive money producers would survive, with extensive overlap in border areas" [Hayek (1978, p. 112)].

Entirely aside from the question of the political forces that such arrangements would generate, we are skeptical of his conjecture, rather agreeing with Benjamin Klein's (1976, p. 514) early judgment that "I do not think that adoption of Hayek's . . . policy recommendation of complete domestic freedom of choice in currency would significantly reduce the amount of monopoly power on currency issue currently possessed by each individual European government."7

So far, neither Hayek's belief that privately produced constant purchasing power moneys would become dominant nor Klein's and our skepticism has any direct empirical basis, but derive rather from an interpretation of historical experience under very different monetary arrangements than those Hayek proposes. However, some direct evidence may emerge in the near future, because of developments within the present system that could facilitate the issuance of constant purchasing power money.

In the United States, the Federal Home Loan Bank Board in 1980 authorized federal savings and loan associations to make price-leveladjusted-mortgage (or PLAM) loans and, in 1982, to accept price-leveladjusted-deposits (PLAD). There seems no reason such deposits could not be readily transferable by checks or their equivalent, which would provide a medium of exchange as well as a unit of account of constant purchasing power. So far, apparently, no savings and loan has taken advantage of this possibility. However, since 1982 disinflation has been the rule, and confidence in a more stable future price level has grown rapidly. A real test will come when and if that confidence is shattered. ${ }^{8}$

Another U.S. development, in the course of being realized as this is written, is the introduction of futures markets in price index numbers [Friedman (1984a)]. The Coffee, Sugar \& Cocoa Exchange has received permission from the Commodity Futures Trading Commission (the federal agency that regulates futures markets) to introduce a futures contract in the consumer price index. Trading in the contract began on June 21, 1985. Such futures markets would enable banks to accept deposits on a price-level adjusted basis and hedge their risk in the 
futures market rather than by matching price-level adjusted liabilities with price-level adjusted assets. This development seems to us the most promising of the recent innovations, in terms of its potential effect on the operation of the monetary system.

An earlier U.S. development was the removal in 1974 of the prohibition against the ownership, purchase and sale of gold by private persons. In principle, it has been possible since then for individuals in private dealings to use gold as a medium of exchange. And there have been some minor stirrings. The Gold Standard Corporation in Kansas City provides facilities for deposits denominated in gold and for the transfer of such deposits among persons by check. However, this is a warehousing operation-a 100 percent reserve bank, as it were-rather than a private currency denominated in gold and issued on a fractional reserve basis. Unfortunately, there are currently legal obstacles to any developments that would enable gold to be used not only as a store of value or part of an asset portfolio but as a unit of account or a medium of circulation. Hence, the current situation provides little evidence on what would occur if those obstacles were removed.

In the U.K., the government now issues securities that link interest and principal to a price index number. Banks could use such securities as assets to match price-level adjusted deposits.

It remains to be seen whether any of these opportunities will be exploited. Our personal view is that they will be if and only if government monetary policy produces wide fluctuations in inflation, fluctuations even wider than those that occurred in the U.S or the U.K. in recent decades. Moreover, even if they are, we conjecture that the use of a constant purchasing power of money as a unit of account and medium of circulation will be confined to large transactions involving long times delays, not to small or current transactions.

A further qualification is that the circumstance envisaged in the preceding paragraph-wide fluctuations in inflation in major countriesis not likely to prove stable and long-lasting. It is almost certain to produce political pressures for major monetary reform -in the extreme, after it has degenerated into hyperinflation; on a more hopeful note, long before.

Until recent years, true hyperinflation has occurred only in countries undergoing revolution or severe civil unrest or that have been defeated in a major war, with the possible exception of John Law's experiment of doubling the French bank-note issue in the four-year period 1716 to 1720. However, currently, several countries seem on the verge of hyperinflation under relatively peaceful circumstances-Bolivia, Argentina and Israel, to mention only the most prominent. The misfortune of these countries promises to provide us with some evidence on a so far rarely observed phenomenon. 
Another recent hybrid development of considerable interest is the increased use of the ECU (European Currency Unit) in private transactions. The ECU is a composite of the separate national currencies of those Common Market countries participating in the European Monetary System-or, as it has come to be described, a basket containing specified numbers of units of each of the national currencies included in it. Its value in terms of any single national currency, including the dollar or any of the currencies composing it, is thus a weighted average of the market values in terms of that currency of the component ECU currencies. Though initially created for clearing intergovernmental balances, it has increasingly been used as a unit of account in private bond issues and other transactions [see Triffin (1984, especially pp. 150-163)], and banks in some countries have been offering ECU denominated deposits, though in others, such as Germany, they are currently not permitted to do so. So far, the ECU has been convertible into dollars and most other currencies. However, it has been in existence only since 1979, so it is still in the early stages of development. What role it will play in the future is highly uncertain.

The ECU is a governmentally created and issued currency. It is convertible only into other governmentally created and issued currencies, all of which are purely fiduciary, despite lip service still paid to gold by including gold, generally at an artificial price, as a "reserve asset" in the balance sheets of the central banks. What is unique is its composite character, resembling in this respect the fiduciary counterpart to the symmetallic proposal by Marshall and the later commodity reserve proposals. ${ }^{9}$

It does offer an alternative to the separate national currencies and so does enhance currency competition. However, its growth and wider use would represent joint government action in the field of money along the lines of the International Monetary Fund, rather than private action. As with national currencies, private action would take the form of producing inside money convertible into the ECU as an outside money.

Items [3] and [4] of Friedman's list of "good reasons," technical monopoly and external effects, have been questioned also by Roland Vaubel (1984) in a thoughtful article. He concludes that neither is a valid justification for a government monopoly in the production of base money.

With respect to natural monopoly, he concludes that "the only valid test of the natural monopoly argument is to abolish all barriers to entry and to admit free currency competition from private issuers on equal terms" [Vaubel (1984, p. 57)]. We agree with him entirely on this point while, as noted earlier, being highly skeptical that, given the starting point with a government currency firmly established, any private issuers would be likely to compete successfully-especially in producing 
a "pure fiduciary" money. As already noted, there is no historical precedent. Historical experience suggests that the only plausible alternative to a government issued fiduciary currency is a commodity currency, with private issuers producing inside money convertible into the commodity. And we believe that even that outcome is highly unlikely unless there is a major collapse of national currencies-something approximating hyperinflation on a worldwide scale.

With respect to externalities, Vaubel's negative conclusion is a quibble with respect to the basic issue of whether government has a key role to play in the monetary system. Even if there are externalities, he says, it "does not follow that government should produce money (let alone as a monopolist) rather than introduce a mandatory deposit insurance scheme or act as a lender of last resort by borrowing and lending private money" [Vaubel $(1984$, p. 32)]. But either of these policies would be a far cry from leaving "money and banking arrangements ... to the market."

To summarize our answer to the first question: there is no economic reason why the determination of a unit of account linked with a medium of exchange and the provision of outside money cannot be left to the market. But history suggests both that any privately generated unit of account will be linked to a commodity and that government will not long keep aloof. Under a wide variety of economic and political circumstances, a monetary system has emerged that rests on a unit of account and on outside money at least certified, and generally more than that, by government. Such a system will not easily be dislodged or replaced by a strictly private system.

\subsection{Free Banking}

A number of recent authors have argued that the historical experience with "free banking" is less unfavorable than suggested by Friedman and other authors. Lawrence White has reexamined the experience in Scotland for the period up to 1845 and concluded that it supports "the case for thorough deregulation" of banking [White (1984a, p. 148)]. Rockoff (1975), Rolnick and Weber (1983) and King (1983) have reexamined the experience in the United States prior to the Civil War and come to a similar conclusion, arguing that prior studies of this period have grossly exaggerated the quantitative importance of "wildcat banking,"' overissue of depreciated bank notes, and the other ills generally associated with banking in that era.

The experience of Scotland, as most recently described by White, is surely the most favorable. For more than a century and a half Scotland had a system of free banking, with completely free entry and minimal governmental regulation or restraint. Scottish banks were banks of 
issue as well as of deposit. Their note issues circulated widely and were in practice the dominant medium of circulation. With minor exceptions the issues of different banks-numbering as many as 29 in 1826 and 19 in 1845 , just before the end of the era of free bankingcirculated at par with one another, thanks to an agreement among the banks to accept one another's notes [White (1984a, pp. 35, 37)]. Some banks did fail, but holders of their notes suffered negligible, if any, losses. And this system developed entirely by market forces, with government intervention consisting solely in the chartering of three of the banks.

However, before accepting the relevance of this experience to our current situation, it is important to note several special features of Scottish experience: first, it dealt only with inside money. Outside money consisted of either gold or, during the period of suspension of convertibility by the Bank of England (1797-1821), Bank of England notes. Second, as White stresses (1984a, p. 41), shareholders of banks assumed unlimited liability for the obligations of the banks. ${ }^{10}$ As a result, bank depositors and holders of bank notes were sheltered from the failure of banks; the whole burden fell on the stockholders. Third, Scotland was an old, established community, with a relatively stable population, so that stockholders consisted in the main of persons who were well known, had considerable private wealth and valued their own reputations for probity highly enough to honor their obligations. ${ }^{11}$ Fourth, while the only equivalent in Scotland itself of a central bank was the extent to which some of the larger banks served as bankers' banks, the Scottish banks had access to the London financial market, which performed the equivalent of some modern central bank functions for Scotland [see Goodhart (1985, sect. 5, note 3)].

For a contrast, consider the experience of the United States from, say, 1791 to 1836, the period spanning the first and second Banks of the United States. New England perhaps came closest to matching Scotland in some of its characteristics, particularly in containing substantial communities with long-settled prominent families possessing much wealth. It was taken for granted that specie was the dominant money and provided the appropriate unit of account. In the main, laissez-faire prevailed in banking, despite the existence of the two Federal banks, as Hammond (1957) calls them. There was nothing that prevented a system from developing along Scottish lines. Yet it did not. Numerous banks were established, which issued bank notes promising to pay specie on demand, yet a wide range of imaginative stratagems were adopted to postpone and impede redemption, and country bank notes circulated in Boston at varying discounts, leading Boston banks to adopt a succession of measures to enforce redemption. The end result was the famous Suffolk Bank system, which developed grad- 
ually from about 1820 on. As Hammond (1957, pp. 554, 556) remarks: "The Suffolk was in effect the central bank of New England. . . The operators of the Suffolk Bank showed laissez-faire at its best." But even here, laissez-faire did not lead to unlimited liability as a rule, though there must have been private bankers who subjected themselves to unlimited liability; it did not lead to the kind of orderly, efficient, monetary system that developed in Scotland.

And the experience of the rest of the country is even less favorable to regarding the Scottish experience as highly relevant to the circumstances of the U.S. in the early decades of the nineteenth century. Various degrees of laissez-faire prevailed in the several states, but nowhere did it lead to unlimited liability, freely interconvertible bank notes, security of both note holders and depositors from loss, and the other favorable characteristics of the Scottish banking system.

Rockoff, Rolnick and Weber, and King may well be right that wildcat banking in the first half of the nineteenth century was less widespread and extensive than earlier writers made it out to be. They may also be correct that the bank failures that occurred owed far more to the legal conditions imposed on bank note issues-namely, that they be "backed" by state or U.S. bonds-and the subsequent depreciation in value of the bonds of a number of states than to irresponsible wildcat banking. Yet none of their evidence is directly relevant to the question of how banking and currency issue would have developed in the absence of state legislation.

Further, conditions have changed drastically in the past century and a half in ways that are particularly relevant to the question whether financial intermediaries should be prohibited from issuing inside money in the form of hand-to-hand currency [our point 2(a) in section 12.1]. We are no longer dealing with a sparsely settled country in which travel is slow and communication between distant points involves long delays. We now have instant communication and rapid means of transport. Book entries have replaced the physical transfer of currency or specie as the principal means of discharging monetary obligations. From being the primary medium of exchange, currency has become the counterpart of a minor fraction of aggregate transactions. Private institutions, both banks and non-banks, issue inside money in the form of traveler's checks redeemable on demand in outside money. The value of such traveler's checks outstanding is now included in the official estimates of all monetary aggregates broader than the monetary base (equal to outside money). ${ }^{12}$ The possibility - and reality-of fraud by financial institutions remains, but under current conditions it seems unlikely to be more serious for hand-to-hand currency than for deposits.

What was a burning issue a century or two ago has therefore become a relatively minor issue today. Moreover, the arguments by Klein and 
Hayek discussed in the preceding section are far more persuasive with respect to permitting the issuance of hand-to-hand inside money than with respect to the possibility that the private market might produce fiduciary outside money, i.e., a non-commodity outside money. While we therefore see no reason currently to prohibit banks from issuing hand-to-hand currency, there is no pressure by banks or other groups to gain that privilege. The question of government monopoly of handto-hand currency is likely to remain a largely dead issue.

The more important questions currently are the other two under this heading: namely, the restrictions, if any, that government should impose on financial intermediaries and the necessity or desirability of a "lender of last resort." Whatever conclusions one may reach about these issues, it seems to us, would currently be valid regardless of the form of the liabilities issued by the financial intermediaries.

In respect of these questions, conditions have changed much less drastically - as the recent liquidity crises arising out of the problems of Continental Illinois Bank and the failure of Home State Savings in Ohio vividly illustrate. These liquidity crises are of the same genus as those that occurred repeatedly during the nineteenth century. Their very different outcomes-no significant spread to other institutions in the Continental Illinois episode; the permanent closing of many Ohio savings and loans and temporary closing of all of them in the quantitatively far smaller Ohio episode-reflect the different way they were handled-and that too evokes historical echoes.

Governor Celeste of Ohio would have benefited greatly from reading and following Walter Bagehot's (1873) famous advice on how to handle an "internal drain": "A panic," he wrote, "in a word, is a species of neuralgia, and according to the rules of science you must not starve it. The holders of the cash reserve must be ready not only to keep it for their own liabilities, but to advance it most freely for the liabilities of others" [Bagehot $(1873$, p. 51)].

The run on the Ohio savings and loan associations precipitated by the failure of Home State Savings could have been promptly stemmed if Bagehot's advice had been followed. It was only necessary for Governor Celeste to arrange with the Federal Reserve Bank of Cleveland and the commercial banks of Ohio-who were apparently more than willing-to lend currency and its equivalent to the savings and loans on the collateral of their temporarily illiquid but sound assets. Once the savings and loans demonstrated their ability to meet all demands of depositors for cash, the unusual demand would have evaporatedas many historical examples demonstrate, including, most recently, the stemming of the liquidity crisis following the Continental Illinois episode.

Instead, Governor Celeste blundered by declaring a savings and loan holiday, repeating the mistaken Federal Reserve policies of 1931 to 
1933, ending in the 1933 bank holiday. As in that case, the final result of not recognizing the differences between a liquidity and a solvency crisis will doubtless be the failure or liquidation of many savings and loans that would have been sound and solvent in the absence of the savings and loan holiday.

These episodes show that what used to be called "the inherent instability" of a fractional reserve banking system is, unfortunately, still alive and well. What they do not show, and what is still an open question, is whether a government "lender of last resort"- a central bank-is necessary and desirable as a cure. It did not prove to be a cure in the U.S. in the 1930s; it did in the Continental Illinois case, as well as in some earlier episodes. And, whether a satisfactory cure or not, is the emergence of a "lender of last resort" a likely or unavoidable consequence of financial development?

In a recent paper, Charles Goodhart, after surveying a wide range of historical evidence, including the studies we have referred to earlier, concludes that the emergence of "lenders of last resort" in the form of central banks was a natural and desirable development arising from the very characteristics of a fractional reserve banking system. The theoretical argument is straightforward and well-known. It rests on the distinction, already referred to, between a liquidity and solvency crisis. A bank or any other institution faces a problem of solvency if its liabilities exceed the value of its assets. The magnitude of the problem is measured by the difference between the two. That difference may be a small fraction of total liabilities, perhaps even less than the equity of the shareholders, so that if the assets could be liquidated in an orderly fashion the institution could pay off all other liabilities in full or for that matter continue as a going institution. The special feature of a fractional-reserve bank is that the bulk of its liabilities are payable on demand-either by contract or usage. Hence, even in the special case assumed, it will face a liquidity problem if its depositors demand payment. Moreover, the bank's liquidity problem will be far larger in magnitude than its solvency problem. ${ }^{13}$ It cannot satisfy its depositors unless it can in some way convert its temporarily illiquid assets into cash.

A liquidity problem is not likely to remain confined to a single bank. The difficulty of one bank gives rise to fears about others, whose depositors, not well-informed about the banks' condition, seek to convert their deposits into cash. A full-blown liquidity crisis of major dimensions can be prevented only if depositors can somehow be reassured. An individual bank may be able to reassure its depositors by borrowing cash on the collateral of its sound assets from other banks and meeting all demands on it. But if the crisis is widespread, that recourse is not available. Some outside source of cash is necessary. A 
central bank with the power to create outside money is potentially such a source.

After the Federal Reserve in the early 1930s failed to perform the function for which it had been established, the U.S. enacted Federal Deposit Insurance as an alternative way to reassure depositors and thereby prevent a widespread liquidity crisis. That device worked effectively for decades, so long as banks were closely regulated-and incidentally sheltered from competition-and so long as inflation remained moderate and relatively stable. It has become less and less effective as deregulation proceeded in an environment of high and variable inflation. In the Continental Illinois case, it had to be supplemented by the Federal Reserve as "lender of last resort."

Insurance of depositors against bank insolvency is of a magnitude that is well within the capacity of private casualty insurance. It could allow for differences among banks in the riskiness of their assets much more effectively than government insurance [see Ely $(1985 \mathrm{a}, \mathrm{b})]$.

A liquidity crisis, whether or not its arises out of an insolvency crisis, as it did with Continental Illinois and Home State Savings of Ohio, and whether or not it spreads to solvent banks, is a different matter. In the U.S., prior to the Federal Reserve, it was dealt with by a concerted agreement among banks to suspend convertibility of deposits into cashto pay deposits only "through the clearing house." In some other countries, such as Canada, nationwide branch banks (subject to extensive government regulation) have preserved confidence sufficiently to avoid liquidity crises.

The U.S. has been almost unique in preserving a unit banking system with numetous independent banks. The current pressures for deregulation and the widening competition in financial intermediation is changing that situation. The barriers against interstate banking are weakening and very likely will ultimately fall completely. Such "non-banks" as Sears Roebuck, Merrill-Lynch, and so on, in most respects are the equivalent of nationwide branch banks. These developments, as they mature, will simultaneously lessen the probability of liquidity crises and increase the magnitude and severity of those that occur. It is therefore far from clear what implications they have for the "lender of last resort" function.

Vera Smith (1936, p. 148) rightly concluded: "A central bank is not a natural product of banking development. It is imposed from outside or comes into being as a result of Government favours." However, as Goodhart's (1985) exhaustive survey of the historical experience indicates, a central bank or its equivalent, once established, reluctantly assumed the responsibility of serving as a lender of last resort because of the reality or possibility of a liquidity crisis. What is impressive about his evidence is the wide range of circumstances-in respect of 
political and economic arrangements-and the long span of time for which that has proved the outcome.

In practice, the lender of last resort function has been combined with control over government outside money. Such a combination has obvious advantages. However, in principle the two functions could be separated, and some proposals for monetary reform would require such separation, if the government were to continue to serve as a lender of last resort. ${ }^{14}$

The existence of a lender of last resort has clearly enabled banks having access to the lender to operate on thinner margins of capital and cash reserves than they would otherwise have deemed prudent. This fact has been used as an argument both for and against the government assuming lender of last resort functions-for, as a way of lowering the cost of financial intermediation; against, as providing an implicit subsidy to financial intermediation. It has also led to the imposition of required reserve ratios, which has turned a subsidy into a tax by increasing the demand for non-interest bearing outside money.

Deregulation of financial intermediaries so that they are free to pay whatever interest is required to obtain funds and to offer a variety of services over broad geographical areas seems clearly desirable on grounds of market efficiency. The open question is whether that is feasible or desirable without a continued role for government in such matters as requiring registration, provision of information, and the imposition of capital or reserve requirements. Moreover, certainly during a transition period, deregulation increases the danger of liquidity crises and so may strengthen the case for a governmental "lender of last resort." 15 That role could perhaps be phased out if market developments provided protection through insurance or otherwise against the new risks that might arise in a deregulated financial system.

Goodhart's argument (1985) that such an outcome, whether desirable or not, is not achievable, can be put to the test, by enlarging the opportunities for private insurance of deposit liabilities. If such insurance became widespread, risk-adjusted premiums could render regulatory restrictions unnecessary. It is more difficult to envision the market arrangements that would eliminate the pressure for a government "lender of last resort."

\subsection{The Future of Fiat Money}

As noted earlier, the nations of the world are for the first time in history essentially unanimously committed to a purely fiat monetary standard. Will Fisher's (1911b) generalization that "irredeemable paper money has almost invariably proved a curse to the country employing it" hold true for the current situation? In some ways that seems to us 
the most interesting and important current scientific question in the monetary area. How it is answered will largely determine the relevance of the issues discussed in the preceding two sections.

We do not believe it is possible to give a confident and unambiguous answer. The experience of such countries as Argentina, Brazil, Chile, Mexico and Israel are contemporary examples of Fisher's generalization, but they are all lesser developed countries that except for chronology may have more in common with the countries Fisher had in mind than with the more advanced Western countries. The experience of those more advanced countries-Japan, the United States and the members of the Common Market-gives grounds for greater optimism. The pressures on government that led to the destruction of earlier irredeemable paper moneys are every bit as strong today in these countries than earlier-most clearly, the pressure to obtain resources for government use without levying explicit taxes. However, developments in the economy, and in financial markets in particular, have produced counter-pressures that reduce the political attractiveness of paper money inflation.

The most important such developments, we believe, are the greater sensitivity and sophistication of both the financial markets and the public at large. There has indeed been an information revolution, which has greatly reduced the cost of acquiring information and has enabled expectations to respond more rapidly and accurately to developments.

Historically, inflation has added to government resources in three ways: first, through the paper money issues themselves (i.e., the implicit inflation tax on outside money holdings); second, through the unvoted increase in explicit taxes as a result of bracket creep; third, by the reduction in the real value of outstanding debt issued at interest rates that did not include sufficient allowance for future inflation. The economic, political and financial developments of recent decades have eroded the potency of all three sources of revenue.

Though outside money remained remarkably constant at about 10 percent of national income from the middle of the past century to the Great Depression, and then rose sharply to a peak of about 25 percent in 1946, it has been on a declining trend since the end of World War II, and is currently about 7 percent of national income. However, for a modern society, with the current level of government taxes and spending, this component is perhaps the least important of the three. Even if outside money as a fraction of income did not decline as a result of inflation which it unquestionably would, a 10 percent per year increase in outside money would yield as revenue to the government only about seven-tenths of 1 percent of national income.

The second component of revenue has very likely been more important. Past rates of inflation have subjected low and moderate income 
persons to levels of personal income tax that could never have been voted explicitly. However, the result has been political pressure that has led to the indexation of the personal income tax schedule for inflation, which largely eliminates this source of revenue.

The third component has also been extremely important. At the end of World War II, the funded federal debt amounted to 6 percent more than a year's national income. By 1967 it was down to about 32 percent of national income despite repeated "deficits" in the official federal budget. Since then it has risen as deficits have continued and increased, but even so only to about 36 percent currently. The reason for the decline in the deficit ratio was partly real growth but mostly the reduction through inflation in the real value of debt that has been issued at interest rates that ex post proved negative in real terms.

The potency of this source of revenue has been sharply eroded by the developments in the financial markets referred to earlier. Market pressures have made it difficult for the government to issue long-term debt at low nominal rates. One result is that the average term to maturity of the federal debt has tended to decline. Except under wartime conditions, it is far more difficult to convert interest rates on short-term debt into ex post negative real rates by unanticipated inflation than to do so for long-term debt. And for both short- and long-term debt, producing unanticipated inflation of any magnitude for any substantial period has become far more difficult after several decades of historically high and variable inflation than it was even a decade or so ago, when the public's perceptions still reflected the effect of a relatively stable price level over long periods.

In the U.K., the resort to government bonds adjusted for inflation eliminates more directly the possibility that government can benefit from ex post negative real interest rates. There have been pressures on the U.S. Treasury to issue similar securities. Those pressures would undoubtedly intensify if the U.S. were again to experience high and variable inflation.

Perhaps if, instead, we experienced several decades of a relatively stable long-run price level, asset holders would again be lulled into regarding nominal interest rates as equivalent to real interest rates. But that is certainly not the case today.

To summarize, inflation has become far less attractive as a political option. Given a voting public very sensitive to inflation, it may currently be politically profitable to establish monetary arrangements that will make the present inconvertible paper standard an exception to Fisher's generalization.

That is a source of promise; it is far from a guarantee that Fisher's generalization is obsolete. Governments have often acted under shortrun pressures in ways that have had strongly adverse long-run con- 
sequences. Israel today offers a conspicuous example. It continues to resort to inflation under conditions that make inflation a poor source of revenue, if, indeed, not itself a drain.

\subsection{Conclusion}

To return to where we started, Friedman's list of the "good reasons" why "monetary arrangements have seldom been left to the market," what alterations are indicated by the experience and writings of the past quarter century?

Point [1], "the resource cost of a pure commodity currency and hence its tendency to become purely fiduciary," has in one sense fully worked itself out. All money is now fiduciary. Yet the resource cost has not been eliminated; it remains present because private individuals hoard precious metals and gold and silver coins as a hedge against the inflation that they fear may result from a wholly fiduciary money. To go farther afield, a new resource cost has been added because a purely fiduciary currency reduces the long-run predictability of the price level. That cost takes the form of resources employed in futures and other financial markets to provide the additional hedging facilities demanded by individuals, business enterprises and governmental bodies. It would be a paradoxical reversal if these new forms of resource costs produced pressure for the reintroduction of commodity elements into money as a way to reduce the resource costs of the monetary system. We do not know of any study that has tried to compare the resource costs of the pre-World War I monetary system and the post-1971 monetary system. That is a challenging task for research [Friedman (1986)].

Point [2], "the peculiar difficulty of enforcing contracts involving promises to pay that serve as a medium of exchange and of preventing fraud in respect of them," remains alive and well, as the recent Continental Illinois and Ohio Savings and Loan episodes demonstrate, and, more indirectly, the much publicized failures in the government bond market. However, the character of the difficulty has changed. It no longer seems any more serious for hand-to-hand currency than for deposits or other monetary or quasi-monetary promises to pay. Moreover, it is now taken for granted that governments (i.e., taxpayers) will completely shield holders of deposit liabilities from loss, whether due to fraud or other causes. The improvements in communication and in the extent and sophistication of financial markets have in some respects increased, in others decreased, the difficulty of enforcing contracts and preventing fraud. They have certainly made it more difficult politically for governments to remain uninvolved.

Point [3], "the technical monopoly character of a pure fiduciary currency which makes essential the setting of some external limit on 
its amount," has been questioned, far more persuasively, we believe, for currencies convertible into a commodity, than for a pure fiduciary currency. We continue to believe that the possibility that private issuers can (in either sense of that term) provide competing, efficient and safe fiduciary currencies with no role for governmental monetary authorities remains to be demonstrated. As a result we believe that this is the most important challenge posed by the elimination of a commodity-based outside money.

Point [4], "the pervasive character of money" and the "important effects on parties other than those directly involved" in the issuance of money, has not been questioned. What has been questioned, and remains very much an open question, is what institutional arrangements would minimize those third party effects. A strong case can be made that government involvement has made matters worse rather than better both directly and indirectly because the failure of monetary authorities to pursue a stable non-inflationary policy renders performance by private intermediaries equally unstable. As yet, there has developed no consensus on desirable alternative arrangements, let alone any effective political movement to adopt alternative arrangements.

Our own conclusion-like that of Walter Bagehot and Vera Smithis that leaving monetary and banking arrangements to the market would have produced a more satisfactory outcome than was actually achieved through governmental involvement. Nevertheless, we also believe that the same forces that prevented that outcome in the past will continue to prevent it in the future. Whether those forces produce or prevent major changes in monetary institutions will depend on developments in the monetary area in the next several decades-and that crystal ball is rendered even more murky than usual by our venture into largely unexplored monetary terrain.

The failure to recognize that we are in unexplored terrain gives an air of unreality and paradox to the whole discussion of private money and free banking. Its basis was well expressed by Walter Bagehot over a century ago, in the context of the free banking issue. Said Bagehot (1873, pp. 66-67, 68-69):

We are so accustomed to a system of banking, dependent for its cardinal function on a single bank, that we can hardly conceive of any other. But the natural system-that which would have sprung up if Government had let banking alone-is that of many banks of equal or not altogether unequal size. . . .

I shall be at once asked-Do you propose a revolution? Do you propose to abandon the one-reserve system, and create anew a manyreserve system? My plain answer is, that I do not propose it: I know it would be childish . . . [A]n immense system of credit, founded on the Bank of England as its pivot and its basis, now exists. The English 
people and foreigners too, trust it implicitly ... The whole rests on an instinctive confidence generated by use and years. ... [I]f some calamity swept it away, generations must elapse before at all the same trust would be placed in any other equivalent. A many-reserve system, if some miracle should put it down in Lombard Street, would seem monstrous there. Nobody would understand it, or confide in it. Credit is a power which may grow, but cannot be constructed (italics added).

Substitute "unit of account" or "outside money" for "credit" in the italicized sentence and it is directly relevant to the outside money issue. What has happened to the role of gold since Bagehot wrote, the way in which it has been replaced by a purely fiat money, is a striking application of Bagehot's proposition. It took "generations" for confidence in gold "generated by use and years" to erode and for confidence to develop in the pieces of paper which for many years after it was meaningless continued to contain the promise that "The United States of America will pay to the bearer on demand — dollars," or words to that effect. Now they simply state "Federal Reserve Note," "One Dollar" or "___ Dollars" plus the statement "This note is legal tender for all debts, public and private." And even now, a half-century after the effective end of the domestic convertibility of government issued money into gold, the Federal Reserve still lists the "Gold Stock," valued at an artificial "legal" price among the "Factors Supplying Reserve Funds." Like old soldiers, gold does not die; it just fades away.

Similarly, as already noted, there are no effective legal obstacles currently in the U.S. to the development of a private "real" (i.e., inflation adjusted) standard as an alternative to the paper dollar, yet, absent a major monetary catastrophe, it will take decades for such an alternative to become a serious competitor to the paper dollar, if it ever does.

The element of paradox arises particularly with respect to the views of Hayek [see especially Hayek (1979, vol. 3)]. His latest works have been devoted to explaining how gradual cultural evolution-a widespread invisible hand process-produces institutions and social arrangements that are far superior to those that are deliberately constructed by explicit human design. Yet he recommends in his recent publications on competitive currencies replacing the results of such an invisible hand process by a deliberate construct-the introduction of currency competition. This paradox affects us all. On the one hand, we are observers of the forces shaping society; on the other, we are participants and want ourselves to shape society.

If there is a resolution to this paradox, it occurs at times of crisis. Then and only then are major changes in monetary and other institu- 
tions likely or even possible. What changes then occur depend on the alternatives that are recognized as available. Decades of academic argument in favor of eliminating Regulation $Q$ and, in a very different area, adopting flexible exchange rates had little or no impact on institutional arrangements until crises made major changes inevitable. The existence of well articulated cases for these changes made them realistic options.

Similarly, the wide-ranging discussion of possible major monetary reforms will have little effect on the course of events if the present fiat system into which the world has drifted operates in a reasonably satisfactory manner-producing neither major inflations nor major depressions. However, the possibility that it will not do so is very realparticularly that it will fall victim to Fisher's generalization and lead to major inflation. When and if it does, what happens will depend critically on the options that have been explored by the intellectual community and have become intellectually respectable. That-the widening of the range of options and keeping them available-is, we believe, the major contribution of the burst of scholarly interest in monetary reform.

\section{Notes}

1. See Acheson and Chant (1973), Brunner (1976), Buchanan (1984), Hetzel (1984) and Kane (1980).

2. In his rediscovery and advocacy of a tabular standard, R. W. R. White (1979), former governor of the Reserve Bank of New Zealand, proposed terming the corresponding unit of account, the "Real."

W. Stanley Jevons $(1890$, pp. 328,331$)$, in recommending a tabular standard of which he says "the difficulties in the way of such a scheme are not considerable," refers to a book by Joseph Lowe (The Present State of England) published in 1822 which contains a similar proposal.

3. See, for example, Brennan and Buchanan (1981).

4. One of us has discussed elsewhere some of the issues involved, and possible reforms for the U.S. See Friedman (1984b).

5. McCallum (1985, p. 25) also makes this point.

6. E.g., George Smith money was a widely used medium of exchange in the Middle West of the U.S. in the 1840s and 1850s. However, when George Smith retired from control of the Wisconsin Marine and Fire Insurance Company, which he created to evade the state of Wisconsin's prohibition of banks of issue, George Smith money went the way of all money. His successors could not resist the temptation of dissipating for short-term gain the "brand name capital" George Smith had built up. See Hammond (1957, p. 613). The Scottish banks discussed by White are another even more impressive example of a competitive issue of convertible money.

7. See also Martino (1984, especially p. 15). 
8. See McCulloch (1980).

9. See Friedman (1951b). Interestingly, F. A. Hayek (1943) was an early supporter of such a proposal.

10. Except for the three chartered banks.

11. The extreme example was Adam Smith's patron, the Duke of Buccleigh, who was a stockholder in the ill-fated Ayr bank and suffered a major loss when it failed in 1772.

12. For banks, the Federal Reserve statistics include traveler's checks with demand deposits, so no separate estimate of their amount is available. Traveler's checks of non-bank issuers total about 3 percent of total currency, less than 1 percent of total M1.

13. For example, Continental Illinois had total deposit liabilities of close to $\$ 30$ billion as of December 31,1983 , and non-performing loans of less than $\$ 2$ billion. Its solvency problem was still smaller, given the presence of an equity cushion.

14. For example, the proposal to freeze the amount of high-powered money. See Friedman (1984b, pp. 48-52).

15. This point is stressed by Summers in his comment on King (1983). He contrasts the possible gain in micro-efficiency of private money with what he regards as the likely loss in macro-efficiency through increased economic instability. However, he simply takes it for granted that government control of money reduces rather than increases economic instability. That is, to put it mildly, far from clear on the basis of historical experience. 